\title{
Effect of different growth regulator combinations on in vitro callusing of walnut (J. regia L.)
}

IMTIYAZAHMAD LONE AUTHOR FOR CORRESPONDENCE:

IMTIYAZ AHMAD LONE, Regional Research Station, (SKUAST-K) WADURA (J\&K) INDIA
Received : 10.03.2017; Revised : 15.05.2017; Accepted : 25.05.2017

\section{Summary}

The present investigation on effect of different growth regulator combinations on in vitro callusing of walnut (J. regia L.) studies using MS medium was carried out in order to document the available genetic variability in walnut germplasm and to select elite walnut genotypes possessing superior attributes and quality traits. During the survey, data was recorded on one hundred fifty two (152) walnut trees growing in different areas of Kashmir valley. The study also involved establishment of response of elite walnut selections to different plant growth regulators in shoot morphogenesis. Woody species have been found to be far more difficult to clone in vitro than herbaceous plants. Poor response of the explants from mature woody species to in vitro manipulation is usually associated with the problem of browning and explant necrosis. The present studies were conducted on forced explants from three walnut selections (SKUAST 002, SKUAST 008, SKUAST 010). Murashiage and Skoog's basal medium supplemented with $0.3 \mathrm{mg} / \mathrm{l}^{-1}$ Benzylamino purine and $0.1 \mathrm{mg} / \mathrm{l}^{-1}$ indole-3-butyric acid the success varied between zero to 63.88 per cent. Data recorded in per cent was transformed to $\operatorname{arc~sin}^{-1}$ values. Accessions revealed a non-significant difference in influencing the callusing of explant tissues after application of the growth regulators. The values for SKUA-002, SKUA-008 and SKUA-010 were 28.08, 25.25 and 28.52 corresponding 27.91, 24.68 and 28.55 per cent callusing, respectively.

Key words : Walnut, Juglans regia L., Variability, Shoot morphogenetic response, Callusing of walnut (J. regia L.)

How to cite this article : Lone, Imtiyaz Ahmad (2017). Effect of different growth regulator combinations on in vitro callusing of walnut (J. regia L.). Asian J. Soil Sci., 12 (1) : 203-209 : DOI : 10.15740/HAS/ AJSS/12.1/203-209. 